\title{
Akupunktur pada Pasien dengan Efek Samping Obat Pascatindakan Anestesi Spinal
}

\author{
Arief Kurniawan, Asep Sekar Ibrahim \\ Departemen Anestesi dan Terapi Intensif Rumah Sakit Dr. Dustira Cimahi
}

\begin{abstract}
Abstrak
Akupunktur secara luas telah digunakan untuk menginduksi analgesi. Akupunktur dapat digunakan sebagai terapi nyeri, alergi, inflamasi, gangguan metabolik, dan pascastrok. Laporan kasus ini bertujuan memaparkan manfaat akupunktur sebagai terapi gangguan akibat efek samping obat. Seorang wanita 59 tahun memiliki keluhan nyeri perut bagian bawah akibat kista ovarium terpuntir. Pasien alergi terhadap hampir seluruh obat yang pernah diminumnya termasuk antibiotik, analgetik, non steroidal anti inflamatory drugs (NSAID), steroid, dan vitamin. Pasien menjalani kistektomi dengan anestesi spinal menggunakan obat anestetik lokal bupivakain 10 mg di Rumah Sakit Dr. Dustira Cimahi pada 20 Juni 2016. Tiga puluh menit pascabedah pasien mengeluh nyeri di daerah operasi dan muncul efek samping obat dengan keluhan pusing, mual, muka terasa bengkak dan tebal, serta kulit kemerahan seluruh tubuh. Pasien diduga mengalami adverse drug reaction (ADR) akibat bupivakain. Pasien diberi tindakan elektroakupunktur dengan pemasangan jarum akupunktur pada titik insisi, Hegu (LI-4), Neikuan (P-6), Sanyinjiao (SP-6), dan Zusanli (S-36) bilateral dialiri listrik 10 mA pada frekuensi $40 \mathrm{~Hz}$ selama 30 menit. Setelah tindakan elektroakupunktur press needle ditempelkan pada titik Hegu sebelah kiri. Keluhan nyeri berangsur menghilang dan akibat efek samping obat tidak dirasakan lagi. Akupunktur dipilih untuk mengatasi nyeri pascaoperasi dan gangguan efek samping obat karena pasien memiliki riwayat alergi obat analgesik dan antialergi. Pada kasus ini akupunktur efektif mengatasi gangguan akibat efek samping obat anestetik lokal pada suntikan spinal.
\end{abstract}

Kata kunci: Adverse drug reaction (ADR), akupunktur, titik akupunktur

\section{Acupuncture on A Patient with Adverse Drug Reaction after Spinal Anesthesia}

\begin{abstract}
Acupuncture is widely used to induce analgesia. Acupuncture can be used in the treatment of pain, allergy, inflammation, metabolic disorders, and post-stroke. This case report aimed to describe the benefits of acupuncture as a therapy of adverse reactions to drug. A-59-year woman was presented weith a complaint of lower abdominal pain due to twisted ovarian cyst. She had a history of allergy to almost all drugs i.e. antibiotics, analgesics, non-steroidal anti-inflamatory drugs (NSAIDs), steroids, and vitamins. Patient underwent cystectomy under spinal anesthetic of $10 \mathrm{mg}$ bupivacaine at Dr. Dustira Hospital Cimahi on June 20,2016 . Thirty minutes post-surgery, she started to complain about the pain in the area of the surgery and the signs-symptoms of allergic reactions occurred (dizziness, nausea, swollen and thick feeling of the face, and reddish skin all over the body). Patient was suspected of having adverse drug reactions (ADR) that was most likely the side effects of bupivacaine. She then received electroacupunture to address the postoperative pain and allergic reaction to bupivacaine. Acupuncture needles were placed at the point of incision consisting of Hegu (LI-4), Neikuan (P-6), Sanyinjiao (SP-6), and Zusanli (S-36) bilateral, electrified with $10 \mathrm{~mA}$ electricity with a frequency of $40 \mathrm{~Hz}$ for 30 minutes. After the electroacupunture was started, the press needle was placed on the left Hegu point. The pain and allergy complaints gradually disappeared. Acupuncture was chosen to treat postoperative pain and adverse drug reactions in this patient because she had a history of allergy to analgesic and anti-allergy drugs. In this particular case, acupuncture has successfully overcome the adverse reactions of local anesthetic drugs in spinal injections.
\end{abstract}

Key words: Acupuncture, acupuncture points, adverse drug reaction (ADR)

Korespondensi: Arief Kurniawan, dr., SpAn, Departemen Anestesi dan Terapi Intensif Rumah Sakit Dr. Dustira Cimahi, Jl. Dr. Dustira, Cimahi, Tlpn 022-6630932, Email fathchair@yahoo.com 


\section{Pendahuluan}

Akupunktur secara luas telah dipergunakan untuk menginduksi analgesi. Terdapat 2 (dua) teknik dalam terapi akupunktur, yaitu akupunktur manual dan elektroakupunktur. Elektroakupunktur adalah bentuk modifikasi akupunktur manual tradisional. Keuntungan elektroakupunktur, yaitu memiliki efek terapi gabungan stimulasi saraf listrik transkutan (TENS) dan akupunktur manual. Kebanyakan penelitian menggunakan elektroakupunktur karena frekuensi, tegangan, serta bentuk dan panjang gelombang dapat distandardisasi. Akupunktur dapat digunakan sebagai terapi nyeri, alergi, inflamasi, gangguan metabolik, dan pascastrok. ${ }^{1,2}$

Pemahaman tentang akupunktur sangat penting bagi tenaga anestesi mengingat akupunktur dapat dimanfaatkan sebagai salah satu modalitas menangani kejadian akibat efek samping obat (ESO) atau adverse drug reaction $(\mathrm{ADR})$, termasuk ESO anestetik yang dapat terjadi selama maupun setelah tindakan anestesi.

Laporan kasus ini bertujuan memaparkan manfaat akupunktur sebagai terapi gangguan akibat efek samping obat anestetik lokal pada suntikan spinal.

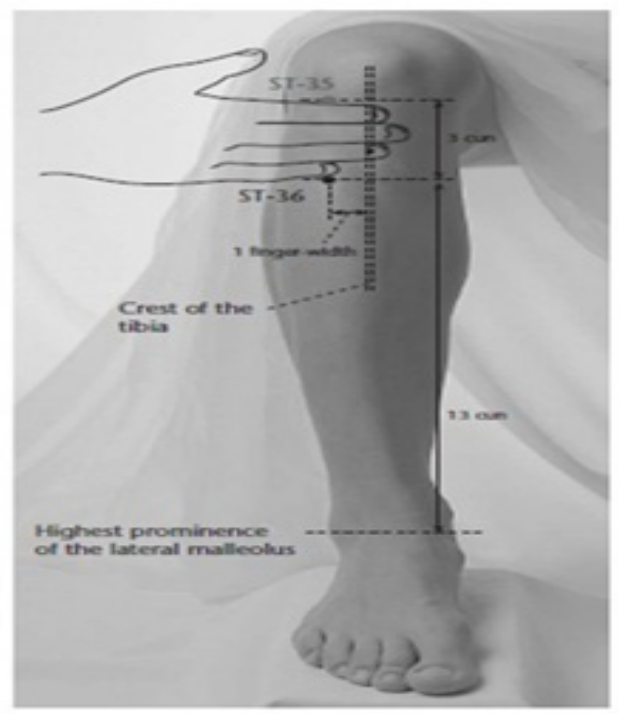

Gambar 1 Titik Zusanli (ST-36)

Dikutip dari: Focks ${ }^{10}$

\section{Deskripsi Kasus}

Seorang wanita 59 tahun dikonsulkan ke Bagian Anestesi Rumah Sakit Dr. Dustira Cimahi pada 20 Juni 2016 dengan keluhan nyeri perut bagian bawah. Nyeri dirasakan sejak satu hari yang lalu dan dirasakan semakin berat, nyeri terasa terus menerus. Awalnya pasien sudah sering mengeluh nyeri seperti ini yang hilang timbul sejak satu tahun yang lalu, kemudian memberat sehingga pasien datang ke rumah sakit. Berdasar atas pemeriksaan didapatkan nyeri tekan pada perut bagian bawah. Hasil ultrasonography (USG) memberikan gambaran kista ovarium ukuran $8 \mathrm{~cm} \times 10 \mathrm{~cm}$.

Pemeriksaan fisis dan laboratorium darah dalam batas normal. Pasien memiliki riwayat alergi terhadap hampir seluruh obat yang pernah diminum seperti antibiotik, analgetik, non steroidal anti inflamatory drugs (NSAID), steroid, dan vitamin. Ketika alergi terjadi maka pasien mengalami gejala kemerahan pada kulit, mual, kepala pusing, dan hidung tersumbat. Diagnosis pasien ini adalah kista ovarium curiga terpuntir dan riwayat alergi obat. Dilakukan tindakan kistektomi dengan anestesi spinal menggunakan obat anestetik lokal bupivakain $10 \mathrm{mg}$ tanpa obat tambahan. Operasi berjalan selama satu jam

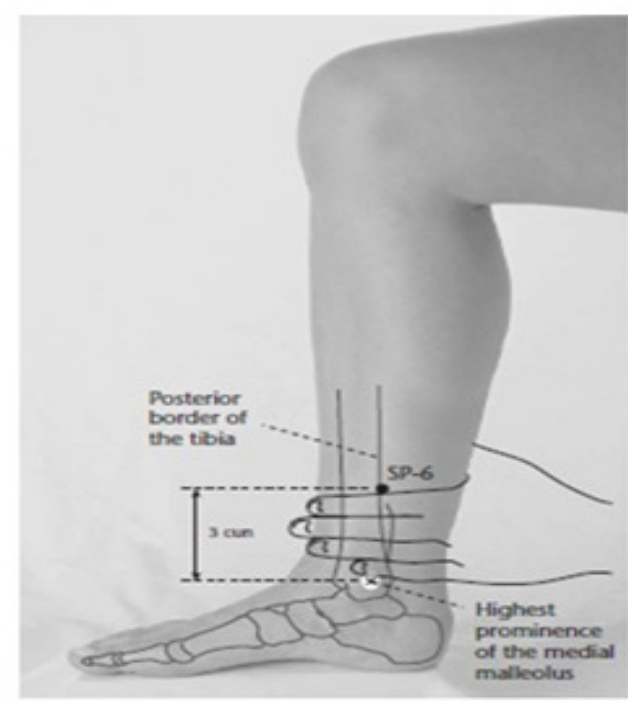

Gambar 2 Titik Sanyinjiao (SP-6)

Dikutip dari: Focks ${ }^{10}$ 
Tabel Bioaktif Kimia dalam Akupunktur

\begin{tabular}{|c|c|c|c|}
\hline Model & Perifer & Medula Spinalis & Supraspinal \\
\hline $\begin{array}{l}\text { Nyeri } \\
\text { inflamasi }\end{array}$ & $\begin{array}{l}\text { Adenosin, } \\
\text { kanabinoit, CB2R, } \\
\text { kortikosteron, COX-2, } \\
\text { CRF, IAM-1, IL-1 } \beta \text {, IL- } \\
\text { 6, PGE2, opiat, TNF- } \alpha\end{array}$ & $\begin{array}{l}\text { 5-HT1AR, 5-HT2AR, kanal ion sensor asam } \\
\text { 3, Akt, } \alpha 2 \text {-adrenoseptor, reseptor dopamin } \\
\text { D2, transporter glutamat-aspartat, } \\
\text { transporter glutamat-1, GluN2A, GluA1, } \\
\text { p-GluN1, glutamat, IL-1 } \beta \text {, IL-6, reseptor } \\
\text { Ach muskarinik, norepinefrin, opiat, } \\
\text { serotonin, substansi P, N/OFQ, p38 MAPK, } \\
\text { P13K, TNF- } \alpha\end{array}$ & $\begin{array}{l}\text { CCK-8, GABA, IL- } \\
\text { 1reseptor tipe 1, } \\
\text { opiat }\end{array}$ \\
\hline $\begin{array}{l}\text { Nyeri } \\
\text { neuropatik }\end{array}$ & $\begin{array}{l}\text { IL-1 } \beta \text {, IL-6, } \\
\text { TNF- } \alpha\end{array}$ & $\begin{array}{l}\text { 5-HT1AR, 5-HT3AR, } \\
\alpha 2 \text {-adrenoseptor, aspartat, COX-2, kinase } \\
\text { regulator ekstraseluler, GABA, GABA } \\
\text { reseptor A, GABA reseptor B, GDNF, GFR } \alpha \text { - } \\
1 \text {, glutamat, glutamin, glisin, IL-1 } \beta \text {, IL-6, } \\
\text { TNF- } \alpha \text {, matriks metalopeptidase-2/-9, } \\
\text { reseptor muskarinik M(1), norepinefrin, } \\
\text { opiat, serotonin, p38 MAPK, PGE2, } \\
\text { somatostatin, anion superoksida, taurin }\end{array}$ & \\
\hline $\begin{array}{l}\text { Nyeri } \\
\text { kanker }\end{array}$ & $\beta$-endorfin & IL-1 $\beta$, dinorfin, substansi P, TRPV1 & $\beta$-endorfin \\
\hline Nyeri viseral & $\begin{array}{l}\beta \text {-endorfin, reseptor } \\
\text { NK- } 1 \text {, substansi P, } \\
\text { reseptor VIP }\end{array}$ & p38 MAPK, serotonin & $\begin{array}{l}\text { 5-HT, } \beta \text {-endorfin, CRF, } \\
\text { GluN1, substansi P }\end{array}$ \\
\hline
\end{tabular}

Dikutip dari: Warner ${ }^{12}$

dengan kondisi hemodinamik stabil tanpa ada keluhan nyeri atau gejala alergi obat. Pasien tidak diberikan antibiotik maupun analgetik prabedah maupun pascabedah, mendapatkan suplementasi berupa oksigen $2 \mathrm{~L} /$ menit dan rumatan infus ringer laktat. Tiga puluh menit pascabedah pasien mulai mengeluh nyeri di daerah operasi dan muncul reaksi alergi dengan keluhan pusing, mual, muka terasa bengkak dan tebal, serta kulit kemerahan di seluruh tubuh. Pasien diduga mengalami reaksi alergi bupivakain. Karena pasien mempunyai riwayat alergi terhadap steroid, NSAID, dan analgetik diputuskan pemberian elektroakupunktur untuk mengatasi nyeri pascaoperasi dan reaksi alergi obat.

\section{Pembahasan}

Berdasar atas kasus ini maka teknik anestesi spinal untuk kistektomi dipilih karena pasien belum pernah mengalami ADR terhadap obat anestetik lokal. Teknik anestesi spinal yang digunakan dengan anestetik lokal tanpa obat tambahan dapat menentukan satu jenis obat sebagai penyebab apabila terjadi ADR. Bila menggunakan anestesi umum maka ada berbagai obat yang digunakan sehingga akan menyulitkan untuk menentukan penyebab dan antisipasi bila terjadi ADR. ${ }^{3}$

Pasien ini mengalami keluhan alergi dan juga nyeri secara bersamaan sehingga membutuhkan obat berupa anti-inflamasi dan analgesik. Keluhan alergi yang muncul pascabedah dengan sebagai anestesi spinal tersebut mengarahkan dugaan penyebab alergi adalah bupivakain. Tata laksana ADR pada kasus ini tidak mungkin menggunakan obat-obatan karena pasien memiliki riwayat alergi obat anti-inflamasi dan analgesik. Teknik akupunktur dipilih untuk mengatasi keluhan alergi dan nyeri karena memiliki efek anti-inflamasi dan analgesik. ${ }^{4,5}$

Adverse drug reaction (ADR) adalah efek obat tidak diinginkan yang timbul pada pemberian obat dengan dosis yang digunakan untuk profilaksis, diagnosis, maupun terapi. Adverse drug reaction timbul sebagai bagian 
dari aksi farmakologis obat yang kejadiannya tidak dapat diperkirakan.

Beberapa reaksi obat dapat timbul pada semua orang, sedangkan beberapa obatlainnya hanya dapat timbul pada orang yang rentan. Alergi obat merupakan reaksi imunologis yang spesifik dan berulang bila terpapar kembali oleh obat yang mencetuskan. Adverse drug reaction (ADR) diperkirakan terjadi hampir $15 \%$ dari pemberian obat. Risiko terjadi ADR dapat meningkat hingga dua kali lipat di rumah sakit. Reaksi obat yang dapat menimbulkan kematian sebesar $0,1 \%$ pada pasien rawat inap dan 0,01\% pada kasus bedah. Hanya 5\% sampai dengan 10\% ADR merupakan alergi obat.

Adverse drug reaction itu memerlukan terapi anti-inflamasi, mengurangi dosis atau menyetop pemberian, dan juga meramalkan bahaya pada pemberian selanjutnya. ${ }^{6,7}$

Tindakan akupunktur pada pasien ini menggunakan titik insisi, Hegu (LI-4), Neikuan (P-6), Sanyinjiao (SP-6), dan Zusanli (S-36) bilateral (Gambar 1 dan 2) yang dialiri listrik 10 mA dengan frekuensi $40 \mathrm{~Hz}$ selama 30 menit. Setelah tindakan elektroakupunktur press needle ditempelkan pada titik Hegu sebelah kiri. ${ }^{8,9}$ Keluhan nyeri berangsur menghilang dengan skor visual analogue scale (VAS) 1-2. Keluhan pusing, mual, muka bengkak, dan kesemutan tidak dirasakan lagi.

Akupunktur akan memengaruhi persarafan jaringan bagian lapisan dalam, otot, jaringan ikat, dan serabut nyeri. Titik akupunktur berada di daerah persarafan yang rapat, terutama anyaman saraf serabut nyeri. Elektroakupunktur merangsang serabut $A \beta$ dan memodulasi nucleus rafe magnus (NRM) untuk menghasilkan analgesi. Akupunktur menimbulkan efek melalui mekanisme sentral dan perifer yang dibuktikan oleh beberapa studi baik terhadap hewan coba maupun pada manusia dan melibatkan berbagai bioaktif kimia/mediator seperti terlihat pada Tabel..$^{11,12}$

Akupunktur frekuensi rendah $(2-15 \mathrm{~Hz})$ dapat melepaskan enkeflin, $\beta$-endorfin, serta endomorfin yang bekerja pada reseptor $\mu$ dan $\delta$. Akupunktur frekuensi tinggi (100 $\mathrm{Hz}$ ) menyebabkan pelepasan dinorfin untuk reseptor $\kappa$ pada saraf spinal. Akupunktur melibatkan opiat, cholecystokinin octapeptide (CCK-8), 5-hydroxytryptamine (5-HT), $N$-methyl D-aspartat-acid (NMDA), dan mediator lain (angiotensin, somatostatin, vasopresin, arginin, dan juga neurotensin) untuk menimbulkan efek anti-inflamasi dan analgesik. . $^{13,14}$

Akupunktur memiliki keuntungan ganda pada kasus ADR karena akupunktur memiliki efek anti-inflamasi dan analgesik. Akupunktur menjadi teknik pilihan untuk mengatasi reaksi alergi pada pasien dengan riwayat alergi terhadap hampir semua jenis obat. Akupunktur dapat dipertimbangkan sebagai teknik anestesi pada pasien yang alergi terhadap obat anestetik bilamana menjalani operasi.

\section{Simpulan}

Elektroakupunktur ternyata efektif mengatasi gangguan akibat efek samping obat anestetik lokal pada suntikan spinal. Elektroakupunktur dapat dipertimbangkan dalam mengatasi gangguan akibat efek samping obat apabila pasien alergi terhadap obat antialergi.

\section{Daftar Pustaka}

1. Ning Z, Lao L. Acupuncture for pain management in evidence-based medicine. J Acupuncture Meridian Studies. 2015;8(5):270-3.

2. Madsen MV, Gotzsche PC. Acupuncture treatment for pain: systematic review of randomised clinical trials with acupuncture, placebo acupuncture, and no acupuncture groups. BMJ. 2009;338(1):118.

3. Becker DE, Reed KL. Local anesthetics: review of pharmacological considerations. Anesth Prog. 2012;59(2):90-102.

4. Zijlstra FJ, Lange IB, Huygen FJ, Klein J. Anti-inflammatory actions of acupuncture, mediators of inflammation. Taylor Francis Health Sci. 2003;12(2):66.

5. Mucuk S, Baser M, Ozkan T. Effects of noninvasive electroacupuncture on labor 
pain, adrenocorticotropic hormone, and cortisol. Altern Ther Health Med. 2013;19(3):26-30.

6. Liu W, Yang X, Lie C. Adverse drug reactions to local anesthetics: a systematic review. Oral Surg Med. 2013;115(3):319-27.

7. Robertson J, David A. Low awareness of adverse drug reaction reporting systems: a consumer survey. Med J Aust. 2013; 199(10):684-6.

8. Lee J, Lee JY, Kim HJ, Seo KS. Dental anesthesia for patients with allergic reactions to lidocaine: two case reports. J Dent Anesth Pain Med. 2016;16(3):20912.

9. Hu C, Zhang $\mathrm{H}, \mathrm{Wu} \mathrm{W}, \mathrm{Yu} \mathrm{W}, \mathrm{Li} \mathrm{Y}$, Bai J, dkk. Acupuncture for pain management in cancer: a systematic review and metaanalysis. Evidence-Based Complementary Alternative Med. 2016;16(1):1-14.
10. Focks C. Atlas of acupuncture. Edisi ke-7. London: Churchill Livingstone; 2008.

11. Leung L. Neurophysiological basis of acupuncture-induced analgesia-an updated review. J Acu Meridian Studies. 2012;5(6):261-70.

12. Warner DS. Mechanisms of acupunctureelectroacupuncture on persistent pain. Anesthesiology 2014;120(1):482-503.

13. Gim GT, Lee JH, Park E, Sung YH, Kim CJ, Hwang WW, dkk. Electroacupuncture attenuates mechanical and warm allodynia through suppression of spinal glial activation in a rat model of neuropathic pain. Brain Res Bull. 2011;86(1):403-11.

14. Gheorghita E, Litarczek G, Trifu M, Rata O, Ciurea J, Gorgan RM. Anesthesia by electroacupuncture in neurosurgery. Romanian Neurosurg. 2010;3(1):348-53. 